\title{
Research on the Motive Force and Path of Logistics Transformation in the Background of Internet +
}

\author{
$\mathrm{Li} \mathrm{Qu}^{1}$, Shuang Wang ${ }^{2}$ \\ ${ }^{1}$ Changchun Institute of Finance and Economics, Changchun, Jilin, 130122 \\ ${ }^{2}$ NO.24 Research Institute of CETC, Chongqing, 400060
}

Keywords: Internet +, Logistics Transformation, Motive Force

\begin{abstract}
Logistics is the first from the United States into China. Since the emergence of this industry, it has rapidly grown up in China's economic market, and even among the people in our country that the logistics industry will become one of the largest industries in this century, through the emergence of the logistics industry in China's economic market Development, this industry does have a lot of complex. Its main function is of course the transport of products, but in the transport process will also involve handling \& packaging and information processing and other fields. However, relative to the development of logistics industry in developed countries, China's logistics industry is still more traditional, although the current competition in this industry is more intense, but most still remain in the price and cost competition. The new norm is now a normal in our society, but since it is called the new, it is because of the situation with the past completely different circumstances, but this anomaly in the future development will become normal, it is because the current China's economic market environment has changed, so many industries need to be based on external changes in the transformation and upgrading in order to better in the new normal to seek development and progress.
\end{abstract}

\section{Introduction}

The new normal economic development is the central strategic judgment. New normal is a trend, is different from the past, relatively stable development of the state. New normal means "abnormal reality is gradually becoming normal", that is, China's current slowdown adjustment is relatively traditional high growth in terms of the new normal, the new normal "new", the key lies in the economic structure and industrial transformation and upgrading. The characteristics of unstable equilibrium determine the new normal state is a typical relatively smooth transition stage, there are opportunities for economic transformation and structural optimization, there are a variety of new obstacles and constraints. Logistics industry as an important producer services, in recent years by the state and the relevant departments attach great importance to the logistics industry in the national economy in the industrial position steadily improved. The logistics industry is the integration of industrial activities such as transportation, packaging, warehousing, loading and unloading. It has the basic and strategic supporting role in the development of the national economy. The specific role is expressed in the following aspects: to promote the steady growth of the total amount, The total logistics of the unit to support a unit of GDP; adjust and optimize the industrial structure, the service industry for each additional 1 percentage point, the logistics industry needs to increase by 6.8 percentage points to drive; cost increase efficiency, social logistics and GDP ratio of each drop of 0.1 percentage points, Equivalent to the added economic benefits of more than 500 
billion; to promote employment Huimin Health, the logistics industry for each additional 1 percentage point, creating about 500,000 jobs. The logistics industry is closely related to the national economic development and has become a pillar industry of the national economy. At the Davos Forum in the summer of 2014, Premier Li Keqiang pointed out that logistics and other tertiary industries are bound to become new economic growth points in the coming period. China Logistics and Purchasing Federation, He Liming that China's logistics industry is in the industrial status of the promotion period, the formation of modern logistics service system and the construction period of logistics power. The face of China's economic development of the new normal stage of the characteristics of the logistics industry should be how to deal with the strategic level?

\section{Development and Change of Logistics Industry under Internet Economy}

The number of courier changes, the number of logistics parcels from 5.7 billion in 2012 to 9.2 billion in 2013, and then to 14 billion in 2014 growth trend. Express changes behind the logistics front-end business changes. (2) changes in demand, in the general acceptance of the transition from B2B to B2C process, Jingdong, Ali, Suning O2O (Online To Offline) and Haier, millet, ZTE's C2B (Custom-ers To Business) development trend in the capture Logistics demand services new value points. (3) changes in logistics carrier, in the high-speed road truck traffic fell $2 \%-5 \%$, the courier business flow increased by 50\% -100\%, SF aircraft reached 34, Debon and other zero-business enterprises increased About 40\%. Logistics carrier in the development of change. (4) business model changes, the new type of Internet business is driven by personalized custom consumption, the traditional mobile phone mode to the C2B millet mode, the traditional home appliance model to Haier's Internet transformation of the DIY model, the traditional Detroit car mode to the Silicon Valley Tesla production car model, 2014 Internet business has evolved from O2O experience to C2B customization services. Internet-based logistics is the C-side drive as the core, personalized custom consumption $+\mathrm{O} 2 \mathrm{O}$ experience, emphasizing the small batch, multi-batch, high-frequency logistics service needs, information replacement inventory is the logistics service model change. In 2015, "Internet +" was written into the government work report, the logistics industry to start in the "Internet +" to find a new way out. "Internet +" situation, the timeliness of information makes the spatial distance is relatively short, which led to the logistics industry speed and rapid integration of the strong demand. Relying on the new model of the Internet economy to change the original rules of the game, the logistics market structure will speed up the adjustment to speed up the reshuffle. "Internet +" logistics needs to change the original logistics mode of operation, the full implementation of information technology, to achieve the wisdom of logistics.

\section{New Normal "Internet +" Logistics Industry to Develop Innovative Consideration}

In 2014, the Internet triggered the major logistics platform of China's successively hatching, logistics park platform, highway port platform, Lingdan logistics green platform, transport resource platform, financial leasing platform, logistics taxi mode platform, platform business model has not yet formed, logistics platform enterprises Of the business model in 2015 to enter the upgrade and innovation period. The Internet is open, infinite, no time constraints, the Internet platform thinking is open, shared, win-win thinking. Logistics platform must be open to thinking to play innovative. Alibaba's ecological model, to help a lot of entrepreneurs wants to use the Internet to achieve the dream of entrepreneurs. Millet "do not work" model, through the logistics platform integration upstream and downstream, their mainstream goods or services do not make money, extended out of 
the service is an important way to profit. 360 free mode quickly occupied the domestic security software market. Logistics platform economy is a new business model based on ecology, is the integration of business model, but also strategic thinking of the coordination, with long-term strategic value, the need for business model fission, access to more value space.

Crowd Founding is the most popular concept of the Internet, because it has a low threshold, diversity, relying on the power of the public and focus on creativity and other characteristics, once put on the Internet was fired uproar. As a decentralized capital of the Internet civilians and grassroots of the mode of operation, is a traditional industry Internet thinking baptism, such as Alibaba's "entertainment treasure", Baidu's "all the channel", Jingdong Prefecture Sale "Minato elements", good warehouse $\mathrm{O} 2 \mathrm{O}$ chain storage. The Internet age is the era of resources and information to make money, and the public as an open and shared thinking, one plus one more than two thinking fit the requirements of the Internet economy. The conditions that need to be done are traffic, derivative services, and financial instruments. The development of all chips is related to the awareness of consumers, and the mode of foreign investment is not new in the domestic market, especially in the logistics industry, has a huge attempt space, it is worth exploring. The Internet field of the various models to apply to the logistics industry - whether it is the capital of the public or the resources of the chips, will bring a lot of imagination.

\section{Transformation and Upgrade of Logistics Enterprises in the Internet}

In the Internet information technology is highly developed today, the logistics industry and other industries between the integration of its further development of the only way. In China, the development of the logistics industry has been working closely with industrial manufacturing and financial sectors. If these industries can be integrated, the logistics efficiency will be greatly increased. Secondly, due to industrial consolidation, Will lead to the integration of resources, is conducive to further extension of the logistics industry services for the logistics industry in China to enhance the quality of service also has a great role in promoting, from a macro point of view, this has a positive impact on the construction of a harmonious society in China.

In the current society, with the development of the Internet, the era of large data has come, which makes the exchange between individual consumers and business organizations more convenient, and with China's material civilization and spiritual civilization to further the construction of people for personalization The pursuit has gradually increased. And this time accurate marketing model came into being, with the Internet technology, but also for the realization of precision marketing to provide external protection, so the logistics industry to further development, we must attach great importance to the marketing of this marketing model, when the logistics enterprises can be accurate Of the customer or potential customers to grasp the relevant information, the quality of service and efficiency will be further enhanced, thereby increasing customer satisfaction and promote the development of enterprises.

The traditional logistics industry is relatively simple, in general, after receiving orders to deal with. In the increasingly fierce competition in the market, this passive form of service has been unable to meet the development needs of the market. Therefore, the establishment of active service awareness and system is to enhance the competitiveness of the key, through the end or mobile phone, you can and potential customers to establish a good communication, passive to take the initiative, so that not only can make customers feel more intimate, this human Of the service system can also add more customers for the logistics business, so as to create more profits for the enterprise.

For the traditional business management, there is a widely circulated words, called the interlaced 
as a mountain, but in the highly developed information and network today has not applicable, so a bold attempt, cross-border cooperation, to achieve a win-win goal, in the But also can promote the development of other industries in China, for the growth of China's national economy, but also to promote the development of China's foreign trade, but also to promote the development of China's foreign trade, Lay the foundation, such as Shun Feng's Hey, successful into the retail electricity business in this industry, but after all, there are some risks cross-border, so in the early should be the main cooperation, adhere to the principle of gradual progress in order to go in the development More robust,

\section{Conclusion}

With the continuous development of society, the current logistics industry has become an important industry to promote China's economic growth, especially in the highly developed Internet today, the development of the logistics industry also ushered in new opportunities and challenges, relatively speaking, logistics China is a new industry, although in recent years the rapid development of the logistics industry, but relative to Europe and the United States developed countries, there is still a great gap in efficiency, in the new normal, this paper is the current development of China's logistics industry This paper puts forward some suggestions on the development and transformation of the logistics industry, and plays a certain guiding role for the development of the logistics industry in our country. It uses the Internet technology to combine the logistics industry and the network to improve the logistics efficiency of the logistics industry in China , For the improvement of China's national economy to contribute.

\section{Acknowledgements}

Research on the Path of Upgrading of Logistics Industry in Jilin Province under the Strategy of "13th Five - Year Plan" and "Internet +" in Jilin Province.

\section{References}

[1] Xie Kong, Zhang Yuanyuan. E-commerce on China's express delivery industry, the impact of architectural space [J]. Architectural knowledge, 2006 (03)

[2] Li Qingwei. New normal road under the railway transport to modern logistics transformation path [J]. Railway freight, 2016 (12)

[3] Liu Ying, Peng Shaobing. Shaoguan railway area Huanggang freight yard expansion program [J]. Railway freight, 2016 (12)

[4] Zhao Guanghui. Transport market price and cost calculation - to China's ten provinces and cities road freight market as an example [J]. China's circulation economy, 2017 (04)

[5] Hou Haitao. Study on Economic and Logistics Agglomeration in Henan Province Based on Spatial Measurement [J]. Statistics \& Decision, 2017 (07) 